\section{A presença de disciplinas voltadas ao projeto de espaços livres de lazer urbano nos cursos de Arquitetura e Urbanismo da Região Sul do Brasil.}

The presence of disciplines focused on the project of free spaces for urban leisure in the Architecture and Urbanism courses in the Southern Region of Brazil..

Joani Paulus Covaleski*, Fabiane Vieira Romano**, Lucienne Rossi Lopes Limberger**, Vanessa De Conto*** usjt

\section{arq.urb}

número 30 ljan-abr de 2021 Recebido: $19 / 07 / 2020$
Aceito: $11 / 03 / 2021$

DOI: $10.37916 /$ arq.urb.vi30.451

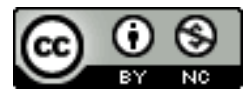

*Graduada em Arquitetura e Urbanismo pela Universidade Regional Integrada do Alto Uruguai e das Missões (2016), e mestra em Arquitetura, Urbanismo e Paisagismo pela Universidade Federal de Santa Maria (2020), cvk.joani@hotmail.com

**Graduada em Engenharia Civil pela Universidade Federal de Santa Maria (1995), mestra em Engenharia de Produção (Projeto de Produto) pela Universidade Federal de Santa Maria (1999) e doutora em Engenharia de Produção (Gestão do Design e do Produto) pela Universidade Federal de Santa Catarina (2003), fabiromano@gmail.com ***Graduada em Arquitetura e Urbanismo pela Universidade Federal do Rio Grande do Sul (1992), e em Desenho e Plástica pela Universidade Federal de Santa Maria (1987), mestra (2000) e doutora (2019) em Planejamento Urbano e Regional pela Universidade Federal do Rio Grande do Sul, lulimbe@gmail.com

*** Graduada em Arquitetura e Urbanismo pela Universidade Luterana do Brasil (2019), mestra em Engenharia de Produção (2017) pela Universidade Federal de Santa Maria, e mestranda em Arquitetura, Urbanismo e Paisagismo pela mesma universidade, vanedeconto@hotmail.com

\section{Palavras-chave:}

Paisagismo.

Espaços livres.

Ensino de projeto.

\section{Keywords:}

Landscaping.

Free spaces.

Project teaching.

\section{Resumo}

Este artigo reflete sobre o ensino de projeto de espaços livres de lazer e recreação urbanos. Com discussões sobre a criação e o entendimento de espaços livres desde as décadas de 1930 e 1940, e com a institucionalização, a partir de 1994, da disciplina de paisagismo e projeto da paisagem nos cursos de Arquitetura e Urbanismo brasileiros, os espaços livres urbanos ganham a importância equivalente a que, até então, era somente atribuída ao espaço edificado. Assim, abre-se espaço para análise da constituição das disciplinas de projeto na grade curricular de cursos de Arquitetura e Urbanismo na Região Sul do Brasil, para entender a presença de projetos de espaços livres de lazer urbano.

\section{Abstract}

This article reflects on the teaching of the design of free urban leisure and recreation spaces. With discussions on the creation and undersanding of free spaces since the 1930s and 1940s, and with the institutionalization, since 1994, of the discipline of landscaping and landscape design in Brazilian Architecture and Urbanism courses, urban free spaces gain the equivalent importance that, until then, was only attributed to the built space. Thus, there is room for analysis of the constitution of the design disciplines in the curriculum of courses in Architecture and Urbanism in the Southern Region of Brazil, to understand the presence of projects for free urban leisure spaces. 


\section{Introdução}

O Arquiteto e Urbanista, atualmente, forma-se um profissional multidisciplinar. Durante a graduação envolve-se com diversas áreas de conhecimento: na arquitetura, com aspectos projetuais e construtivos em diversas escalas; no urbanismo com a sociedade, planejamento e intervenções urbanas; e, no paisagismo, com a vegetação, os espaços livres e as relações entre natureza e meio urbano. Além disso, toma conhecimento de outros aspectos voltados a projetação e ao bem-estar dos usuários, como conforto térmico, acústico, lumínico e ergonômico; eficiência energética e ambiental; sistemas estruturais, elétricos e hidráulicos; e tecnologias computacionais e de representação.

De modo geral, este ofício permeia os campos da arte e da técnica e, nas palavras de Lucio Costa, pode ser definido como uma concepção cuja intenção é "ordenar e organizar plasticamente o espaço, em função de uma determinada época, de um determinado meio, de uma determinada técnica e de um determinado programa" (COSTA, 1952, p. 5).

Voltando um pouco no tempo, nota-se que nas décadas de 1930 e 1940 o ensino de projeto arquitetônico, assunto primordial nas escolas de Arquitetura e Urbanismo, passou a conciliar suas discussões com a criação e o entendimento de espaços livres. A partir desse período, se iniciam estudos sobre questões ambientais e paisagísticas na escala urbana e regional, havendo mudanças na conceituação, constituição e formulação dos espaços livres. Nesse momento, o paisagismo, cujo símbolo primordial era a vegetação, ganha nova visibilidade e passa a ser caracterizado como um dos componentes que constituem a paisagem urbana (ROBBA; MACEDO, 2002; FEGHALI, 2013).

Em 1994, o ensino de paisagismo é instituído como matéria profissional nos cursos de Arquitetura e Urbanismo do Brasil, e passa a ser presença obrigatória na composição da grade curricular, juntamente com as disciplinas de projeto arquitetônico e projeto urbanístico.

Nesse prospecto, abre-se espaço para compreender como, atualmente, os cursos contemplam o ensino de projeto e como é a presença de disciplinas voltadas ao projeto de espaços livres de lazer e recreação urbanos.

\section{Os cursos de Arquitetura e Urbanismo no Brasil}

O ensino de Arquitetura e Urbanismo brasileiro teve dois grandes modelos influenciadores, durante a sua definição no século XX: o modelo da École des Beaux-Arts e o modelo Bauhaus (ALMEIDA, 2001). O primeiro, baseava seu aprendizado em palestras, estágios e na prática profissional desenvolvida nos escritórios de arquitetura. Enquanto isso, no arquétipo Bauhaus, os alunos tinham uma formação básica inicial e após, faziam escolhas para especializações em ateliês, variando entre: tecelagem; pintura mural; marcenaria; artes gráficas; arquitetura entre outras.

Em se tratando da arquitetura da paisagem, como concebida atualmente, foi formalizada na Europa, principalmente na França e Inglaterra, e nos Estados Unidos no século XIX. Sendo um período de mudanças sociais e urbanas, o crescimento da população induziu a novas demandas, e uma delas foi a necessidade de projetação dos espaços livres urbanos (MACEDO, 2003).

Já a introdução do ensino de paisagismo nos cursos de Arquitetura e Urbanismo tem seu início a partir das décadas de 1920 e 1930, quando ocorrem reflexões acerca do tema, atentando-se principalmente à necessidade de democratização das estruturas de ensino e da prática urbanística no Brasil (FEGHALI, 2013). Nesse contexto ressaltam-se as proposições de Lúcio Costa, que busca separar o ensino da arquitetura e do paisagismo das Belas Artes e introduzir no currículo o ensino de urbanismo e paisagismo.

Os espaços livres urbanos ganham a importância equivalente a que até então era somente atribuída ao espaço edificado. A vegetação, o símbolo primordial do paisagismo, a partir das reflexões anteriores e presentes até aquela época, passa a ser entendida apenas como um dos vários elementos constitutivos da paisagem (ROBBA; MACEDO, 2002). Perdem-se os intuitos maquiadores que a vegetação possui no projeto arquitetônico, reflexo inclusivo da modificação da formação dos profissionais.

Macedo (2003), afirma a importância desse período para o ensino de paisagismo, salientando que a mudança no tratamento e na visão sobre os espaços livres, ocorrida nos anos de 1930 e 1940, momento em que as vanguardas negavam o passado recente, refletiu no tratamento do espaço livre urbano, público e privado. 
Joani Paulus Covaleski, Fabiane Vieira Romano, Lucienne Rossi Lopes Limberger e Vanessa De Conto

A presença de disciplinas voltadas ao projeto de espaços livres de lazer urbano nos cursos de Arquitetura e Urbanismo da Região Sul do Brasil

As reflexões ocorridas neste período resultaram em mudanças no final dos anos 1980, alterando a estrutura curricular da disciplina de projeto de paisagismo. Essa mudança de postura pode ser definida como um catalisador na compreensão da importância da paisagem, incorporando mudanças à questão ambiental, ao estudo da escala urbana e regional, e ainda à conceituação, constituição e formulação dos espaços livres de edificação e urbanização (FEGHALI, 2013).

No Brasil é com a instituição da Portaria n.․ 1.770, em 21 de dezembro de 1994, pelo Ministério da Educação (MEC, 1994), que são fixadas diretrizes curriculares e conteúdos mínimos ao curso de graduação em Arquitetura e Urbanismo. Divididos em três partes interdependentes, o conteúdo dos cursos deve ser formado por Matérias de Fundamentação; Matérias Profissionais e o Trabalho Final de Graduação. O Quadro 1 compila o conteúdo mínimo das matérias:

Quadro 1: Matérias e conteúdos obrigatórios aos cursos de graduação em Arquitetura e Urbanismo. Fonte: Elaborado com base na Portaria no 1.770/94 (MEC, 1994, grifo nosso).

\begin{tabular}{|c|c|}
\hline \multicolumn{2}{|r|}{ Matérias de Fundamentação } \\
\hline $\begin{array}{l}\text { Estética, his- } \\
\text { tória das ar- } \\
\text { tes }\end{array}$ & $\begin{array}{l}\$ 11^{\circ} \text { - O estudo de Estética deve estar em conexão com o da His- } \\
\text { tória das Artes e dará ênfase às manifestações ocorridas no Bra- } \\
\text { sil. }\end{array}$ \\
\hline $\begin{array}{l}\text { Estudos so- } \\
\text { ciais ambi- } \\
\text { entais }\end{array}$ & $\begin{array}{c}\S 2^{0} \text { - Os Estudos Sociais e Ambientais objetivam analisar o de- } \\
\text { senvolvimento econômico, social e político do País, nos aspectos } \\
\text { vinculados à Arquitetura e Urbanismo, e despertar a atenção crí- } \\
\text { tica para as questões ambientais. }\end{array}$ \\
\hline Desenho & $\begin{array}{l}\S 3^{\circ} \text { - O estudo do Desenho deve abranger, além das geometrias } \\
\text { e suas aplicações, todas as modalidades expressivas como mo- } \\
\text { delagem, plástica e outros meios de expressão e representação. }\end{array}$ \\
\hline \multicolumn{2}{|r|}{ Matérias Profissionais } \\
\hline $\begin{array}{l}\text { História e } \\
\text { Teoria da Ar- } \\
\text { quitetura e } \\
\text { Urbanismo. }\end{array}$ & $\begin{array}{c}\S 1^{\circ} \text { - O estudo da História e da Teoria da Arquitetura e Urba- } \\
\text { nismo deve envolver o contexto histórico da produção da Arquite- } \\
\text { tura e do Urbanismo, abrangendo os aspectos de fundamenta- } \\
\text { ção conceitual e metodológica. }\end{array}$ \\
\hline $\begin{array}{l}\text { Técnicas } \\
\text { Retrospecti- } \\
\text { vas. }\end{array}$ & $\begin{array}{l}\S 2^{\circ} \text { - O estudo das Técnicas Retrospectivas deve incluir a con- } \\
\text { servação, restauro, reestruturação e reconstrução de edifícios e } \\
\text { conjuntos urbanos. }\end{array}$ \\
\hline $\begin{array}{l}\text { Projeto de } \\
\text { Arquitetura, } \\
\text { de Urba- } \\
\text { nismo e de } \\
\text { Paisagismo. }\end{array}$ & $\begin{array}{c}\text { § 3o - O Projeto de Arquitetura, de Urbanismo e de Paisa- } \\
\text { gismo constitui a atividade criadora, referente à arquitetura } \\
\text { das habitações e edifícios em geral, bem como a projetos de } \\
\text { objetos, paisagens, cidades e regiões. Os temas devem } \\
\text { abordar problemas de maior interesse social, mediante aten- } \\
\text { ção crítica às necessidades sociais. }\end{array}$ \\
\hline
\end{tabular}

\begin{tabular}{|c|c|}
\hline $\begin{array}{l}\text { Tecnologia } \\
\text { da Constru- } \\
\text { ção }\end{array}$ & $\begin{array}{c}\text { § } 4^{\circ} \text { - Na Tecnologia da Construção devem ser incluídos os estu- } \\
\text { dos relativos aos materiais e técnicas construtivas, instalações e } \\
\text { equipamentos prediais e a infraestrutura urbana. }\end{array}$ \\
\hline $\begin{array}{l}\text { Sistemas } \\
\text { Estruturais }\end{array}$ & $\begin{array}{c}\text { § 50 - Os Sistemas Estruturais devem considerar, além do que } \\
\text { lhe é peculiar, o estudo da resistência dos materiais, estabilidade } \\
\text { das construções e do projeto estrutural, utilizando o instrumental } \\
\text { da matemática e da física. }\end{array}$ \\
\hline $\begin{array}{l}\text { Conforto } \\
\text { Ambiental }\end{array}$ & $\begin{array}{c}\S 6^{\circ} \text { - Em Conforto Ambiental deve ser compreendido o estudo } \\
\text { das condições térmicas, acústicas, lumínicas e energéticas e os } \\
\text { fenômenos físicos a elas associados, como um dos condicionan- } \\
\text { tes da forma e da organização do espaço. }\end{array}$ \\
\hline Topografia & $\begin{array}{c}\S 7^{0} \text { - A matéria Topografia deve consistir no estudo da topogra- } \\
\text { fia propriamente dita, com o uso de recursos de aerofotograme- } \\
\text { tria, topologia e fotointerpretação, aplicados à Arquitetura e Urba- } \\
\text { nismo. }\end{array}$ \\
\hline $\begin{array}{l}\text { Informática } \\
\text { Aplicada à } \\
\text { Arquitetura e } \\
\text { Urbanismo }\end{array}$ & $\begin{array}{l}\text { § } 8^{\circ} \text { - O estudo da Informática Aplicada à Arquitetura e Urba- } \\
\text { nismo deve abranger os sistemas de tratamento da informação e } \\
\text { representação do objeto aplicados à Arquitetura e Urbanismo, } \\
\text { implementando a utilização do instrumental da informática no co- } \\
\text { tidiano do aprendizado. }\end{array}$ \\
\hline $\begin{array}{l}\text { Planeja- } \\
\text { mento Ur- } \\
\text { bano e } \\
\text { Regional }\end{array}$ & $\begin{array}{c}\text { § 9o - O Planejamento Urbano e Regional deve constituir-se de } \\
\text { atividade de estudos, análises e intervenções no espaço urbano, } \\
\text { metropolitano e regional. }\end{array}$ \\
\hline
\end{tabular}

O ensino do urbanismo e paisagismo, que geralmente aborda o projeto de parques urbanos, objeto deste estudo, nem sempre esteve presente nos cursos de graduação em arquitetura. Inserido como matéria profissional há 25 anos, o paisagismo, que vai além da própria vegetação e sua disposição, possui diferentes abrangências nas Instituições de Ensino Superior. Normalmente, as disciplinas inerentes à área paisagística abordam projeto de praças, parques e espaços urbanos, além de conhecimento sobre história e diferentes tipos de vegetação.

\section{O projeto em Arquitetura e Urbanismo}

Considerando que cabe ao arquiteto e urbanista, como função primordial projetar espaços em prol do usuário, evidencia-se que "o ato de projetar envolve a capacidade de analisar e avaliar situações, coordenadas à possibilidade de um pensamento criativo para a elaboração de soluções e alternativas adequadas" (FEGHALI, 2013, p. 15).

No ensino de projeto em arquitetura o aprender é tido através do fazer, sendo esta a principal diferença entre o ensino de outras disciplinas: o aluno participa no seu 
Joani Paulus Covaleski, Fabiane Vieira Romano, Lucienne Rossi Lopes Limberger e Vanessa De Conto

A presença de disciplinas voltadas ao projeto de espaços livres de lazer urbano nos cursos de Arquitetura e Urbanismo da Região Sul do Brasil

próprio aprendizado e o professor atua como um interpretador das dificuldades e problemas (VIDIGAL, 2004).

Mahfuz (2004) enfatiza sobre a educação em arquitetura que "se o projeto não pode ser ensinado como dizem muitos, certamente pode ser aprendido". Aprendizado este que, segundo o autor, se dá pela "própria prática de projetos, pela repetição de um procedimento e pelo acúmulo de conhecimentos que acarreta".

Nesse momento, cabe relacionar que o papel do professor no ensino de projeto é participar como interpretador de dificuldades. $O$ docente deve auxiliar nos aspectos relacionados ao objeto de projeto, evitando expor opiniões que sejam relacionadas tão-somente ao gosto pessoal (PIÑóN, 2009).

Mahfuz (2007) ainda acrescenta que para que o aprendizado e a prática de projeto tenham efetividade e relevância, é necessário a realização de pesquisas neste processo, visto que, sem o seu apoio, há o risco de transformar a transmissão de conhecimento em uma apenas uma passagem de opiniões do professor para o aluno, tornando-os profissionais mal preparados para a prática e os desafios que podem ser encontrados.

Vargas (2007), em seu trabalho sobre o ensino e a aprendizagem em Arquitetura e Urbanismo, apresenta no Quadro 2, que o processo pode ser dividido em paralelo a seis objetivos de domínio cognitivo.

Quadro 2: Objetivos no domínio cognitivo e exemplificação no ensino de Arquitetura e Urbanismo

\begin{tabular}{|c|c|}
\hline \multicolumn{2}{|c|}{ Fonte: Vargas, 2007, p. 109.} \\
\hline $\begin{array}{l}\text { Objetivos no domínio cog- } \\
\text { nitivo }\end{array}$ & - Exemplos na arquitetura e urbanismo \\
\hline $\begin{array}{l}\text { Conhecimento (como um } \\
\text { produto): Envolve a habili- } \\
\text { dade de lembrar ou recor- } \\
\text { dar-se de informações ou } \\
\text { experiências específicas. }\end{array}$ & $\begin{array}{l}\text { - } \quad \text { Definir "coeficiente de aproveitamento". } \\
\text { - Citar três obras da arquitetura moderna e } \\
\text { seus autores. } \\
\text { - Citar três agentes produtores do espaço } \\
\text { urbano. }\end{array}$ \\
\hline $\begin{array}{l}\text { Compreensão: Envolve o } \\
\text { entendimento e a percep- } \\
\text { ção; necessita do proces- } \\
\text { samento de informações. }\end{array}$ & $\begin{array}{l}\text { - Explicar a possibilidade de verticalização, } \\
\text { tendo como base a relação entre coefici- } \\
\text { ente de aproveitamento e a taxa de ocu- } \\
\text { pação máxima. } \\
\text { - Explicar a diferença entre os conceitos de } \\
\text { adensamento e verticalização. }\end{array}$ \\
\hline $\begin{array}{l}\text { Aplicação: A partir de uma } \\
\text { teoria ou regra geral, }\end{array}$ & $\begin{array}{l}\text { - A partir da planta de cobertura apresen- } \\
\text { tada, construir um elemento }\end{array}$ \\
\hline
\end{tabular}

\begin{tabular}{|c|c|}
\hline $\begin{array}{l}\text { aplica-se a um caso espe- } \\
\text { cífico. }\end{array}$ & $\begin{array}{l}\text { tridimensional que corresponda a ela. } \\
\text { Dado um terreno, seu coeficiente de apro- } \\
\text { veitamento e taxa de ocupação máxima, } \\
\text { dar cinco possibilidades de implantação } \\
\text { para o edifício. }\end{array}$ \\
\hline $\begin{array}{l}\text { Análise: Divisão do todo } \\
\text { em partes, buscando de- } \\
\text { terminar a natureza dos re- } \\
\text { lacionamentos entre eles. }\end{array}$ & $\begin{array}{l}\text { - Caracterizar os agentes de produção do } \\
\text { espaço urbano e seus conflitos. } \\
\text { Tendo como base o programa de projeto } \\
\text { apresentado, indicar quais elementos po- } \\
\text { dem inviabilizá-lo (limite de custos, ter- } \\
\text { reno, restrições urbanísticas, tecnologia). }\end{array}$ \\
\hline $\begin{array}{l}\text { Síntese: Combinação de } \\
\text { elementos para formar um } \\
\text { todo coerente, uma uni- } \\
\text { dade. Está diretamente li- } \\
\text { gada ao pensamento e a } \\
\text { criatividade. Envolve rela- } \\
\text { ções abstratas. }\end{array}$ & $\begin{array}{l}\text { - } \quad \text { Explicar a produção do espaço urbano. } \\
\text { Dados o programa, limites de custos, tipo } \\
\text { de acabamento, terreno, restrições urba- } \\
\text { nísticas, desenvolver o projeto. }\end{array}$ \\
\hline $\begin{array}{l}\text { Avaliação: Trabalha com } \\
\text { elementos e julgamento de } \\
\text { valor que podem ser inter- } \\
\text { nos ou externos. }\end{array}$ & $\begin{array}{l}\text { - } \quad \text { Realizar uma avaliação da legislação de } \\
\text { uso e ocupação do solo, em relação à } \\
\text { qualidade ambiental urbana. } \\
\text { Dado o projeto, fazer uma avaliação quali- } \\
\text { tativa (interna) e comparar com os demais } \\
\text { (externa). }\end{array}$ \\
\hline
\end{tabular}

Esses domínios cognitivos, quando trabalhados em sala de aula, tal como nos exemplos apresentados, podem favorecer o desenvolvimento das conexões cognitivas necessárias ao processo projetual. Além disso, Vargas (2007), ao parafrasear Morin (2000), ainda expressa que a educação, tanto quanto a produção de conhecimento, deve favorecer a aptidão natural da mente em formular e resolver problemas, buscando o estímulo do uso total da inteligência pelo exercício da curiosidade, de modo que o interesse pelo saber seja despertado.

Assim para entender como o ensino de projeto de espaços livres de lazer e recreação tem sido realizado na grade curricular dos cursos de Arquitetura e Urbanismo da Região Sul do Brasil, como se relaciona com as demais disciplinas e com as habilidade e competências objetivadas pelas IES, foram feitas análises com base nos dados fornecidos pelo Ministério da Educação, em sua plataforma online eMEC. Os critérios para definição da amostra e o estudo pormenorizado são explicados a seguir. 


\section{Metodologia}

Com o uso da plataforma online e-MEC (https://emec.mec.gov.br/), a qual reúne os dados de todas as instituições de ensino superior do Brasil, e com base na necessidade de entender como os cursos de Arquitetura e Urbanismo da região sul (RS, $\mathrm{SC}$ e PR), abordam o projeto de espaços livres de lazer e recreação, foram compiladas informações na busca da constituição de um panorama, catalogando dados no período entre agosto de 2018 e junho de 2020.

Primeiro, o que se nota no país, é que atualmente o ensino de Arquitetura e Urbanismo está presente em todos os estados, realidade distante da inicial. Ao todo, existem 811 cursos de Arquitetura e Urbanismo com aprovação dada pelo Ministério da Educação (MEC, 2020), destes 799 estão em atividade — cuja distribuição pode ser vista na Figura $1-\mathrm{e}, 12$ foram extintos.

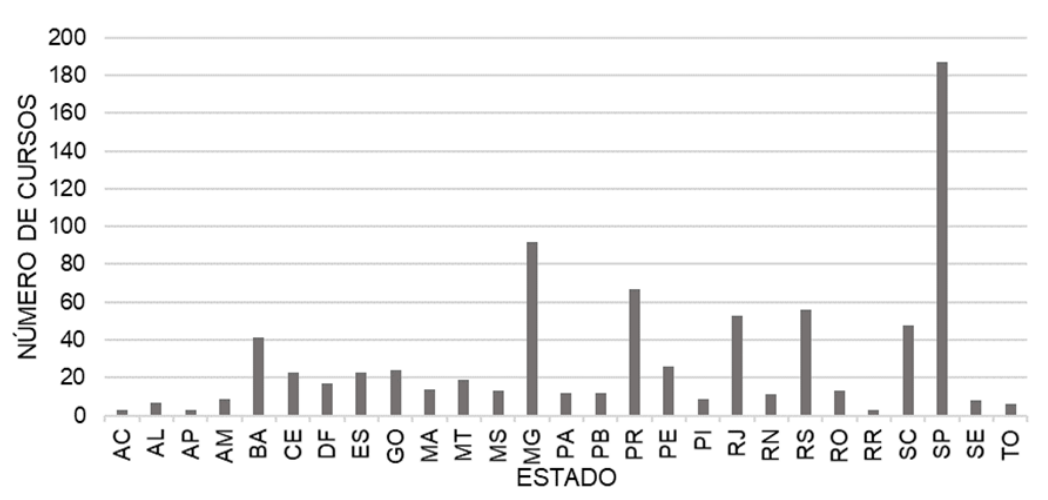

Figura 1: Número de cursos de arquitetura e urbanismo ofertados por unidade federativa Fonte: Elaborado pela autora com base em e-MEC (MEC, 2020).

Além disso, pode-se observar que grande parte dos cursos de Arquitetura e Urbanismo do país concentram-se na região Sul (171) e Sudeste (355), perfazendo um total de 526 cursos (Figura 2).

\section{Número de cursos em atividade por região}

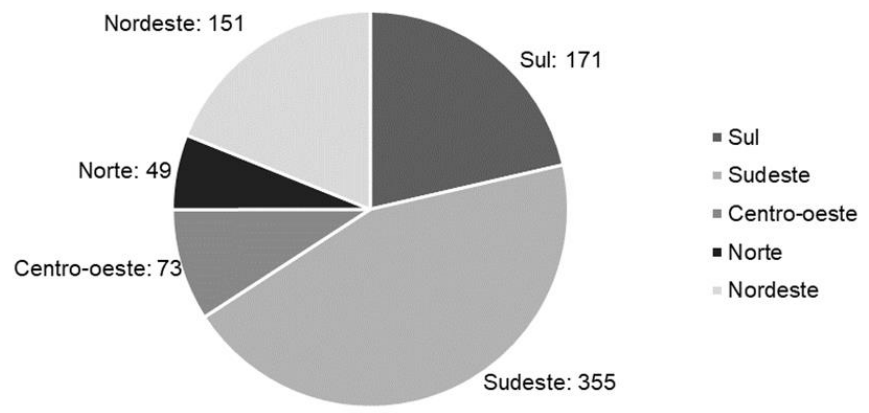

Figura 2: Número de cursos de Arquitetura e Urbanismo por região. Fonte: Elaborado com base em e-MEC (MEC, 2020).

Analisando ainda os 799 cursos de Arquitetura e Urbanismo nota-se que a disciplina de projeto se apresenta como condutora no processo de ensino, ligada aos campos especíicos vemos a sua forte presença em Projeto de Arquitetura, Projeto Urbano e Projeto de Paisagismo. Em função das demandas profissionais após a formação, a disciplina de projeto arquitetônico se destaca em relação às demais (Figura 3):

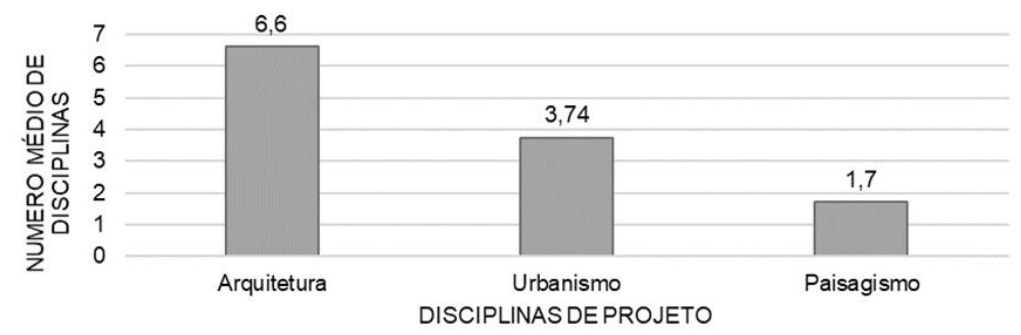

Figura 3: Média de disciplinas de projeto dos cursos de Arquitetura e Urbanismo brasileiros. Fonte: Elaborado pela autora com base em e-MEC (MEC, 2020).

Para entender as abordagens existentes nas disciplinas de projeto de paisagismo e/ou daquelas que possam envolver o aprendizado do processo de projeto de parques urbanos em diferentes escalas, buscou-se a definição de um recorte geográfico. 
Joani Paulus Covaleski, Fabiane Vieira Romano, Lucienne Rossi Lopes Limberger e Vanessa De Conto

A presença de disciplinas voltadas ao projeto de espaços livres de lazer urbano nos cursos de Arquitetura e Urbanismo da Região Sul do Brasil

Nesse momento destaca-se o contexto do ensino de Arquitetura e Urbanismo na Região Sul do país, que apresenta um legado de quase 70 anos e, mesmo que inicialmente abrigasse poucos cursos, no último decênio, essa qualificação se espalhou com vigor em diversos municípios, possuindo características peculiares conteúdo curricular, carga horária mínima, e perfil profissional — as quais permitem indagar como o ensino de paisagismo tem sido ministrado (ROSANELI, 2015). Neste prospecto, define-se como recorte de análise, os cursos de graduação da Região Sul do Brasil, o que se justifica pelo seu legado e pela similaridade climática e cultural.

Outro critério adotado para esta pesquisa é a consideração apenas de cursos cuja nota de avaliação dada pelo Exame Nacional de Desempenho de Estudantes (Enade) tenha sido maior que 2. Vale ressaltar que o Enade classifica os melhores cursos, com notas que vão de 1 a $5^{1}$, sob a responsabilidade do Instituto Nacional de Estudos e Pesquisas Educacionais Anísio Teixeira (INEP), o qual avalia trienalmente o rendimento dos concluintes em relação aos conteúdos do programa, às habilidades e competências que devem ser adquiridas em sua formação.

Assim, dos 799 cursos de Arquitetura e Urbanismo em andamento no país, 202 possuem avaliação dentro dos parâmetros estabelecidos, sendo 107 destes da região sul. A Figura 4 apresenta a distribuição das avaliações:

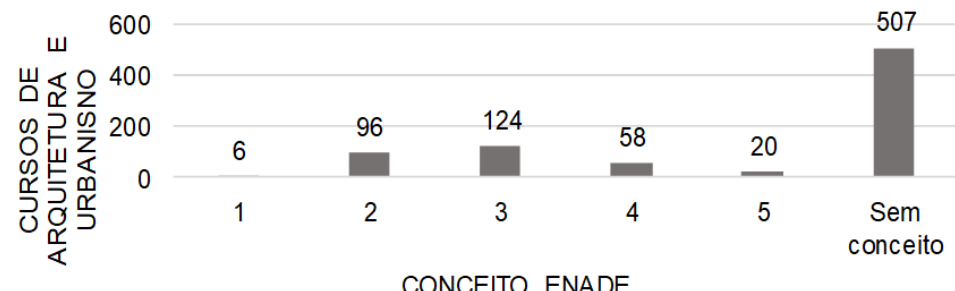

Figura 4: Conceito Enade dos cursos de Arquitetura e Urbanismo. Fonte: Elaborado pela autora com base em e-MEC (MEC, 2020).

De modo geral, para elaboração do elenco de cursos cujo currículo será analisado, sintetizam-se as etapas, os critérios de filtragem e as justificativas no Quadro 3:
Quadro 3: Etapas de filtragem de cursos de ensino superior em Arquitetura e Urbanismo do Brasil.

\begin{tabular}{|c|c|c|c|}
\hline $\begin{array}{l}\text { Etapa de fil- } \\
\text { tragem }\end{array}$ & Critério & Justificativa & $\begin{array}{l}\text { Número } \\
\text { de } \\
\text { cursos }\end{array}$ \\
\hline $\begin{array}{c}\text { Modalidade } \\
\text { de ensino }\end{array}$ & $\begin{array}{c}\text { Somente cursos } \\
\text { de ensino pre- } \\
\text { sencial }\end{array}$ & $\begin{array}{l}\text { Os cursos com ensino a dis- } \\
\text { tância ainda são novos no } \\
\text { aspecto histórico. }\end{array}$ & 799 \\
\hline $\begin{array}{l}\text { Cursos inicia- } \\
\text { dos }\end{array}$ & $\begin{array}{l}\text { Somente cursos } \\
\text { em andamento, } \\
\text { passível de veri- } \\
\text { ficação do pro- } \\
\text { cesso }\end{array}$ & $\begin{array}{c}\text { Visando a credibilidade das } \\
\text { ementas das disciplinas, no } \\
\text { prospecto de já terem sido } \\
\text { aplicadas. }\end{array}$ & 636 \\
\hline $\begin{array}{l}\text { Regiões do } \\
\text { país }\end{array}$ & $\begin{array}{l}\text { Similaridade cli- } \\
\text { mática e proxi- } \\
\text { midade territo- } \\
\text { rial: Região Sul }\end{array}$ & $\begin{array}{l}\text { Os três estados que com- } \\
\text { põem a região possuem cli- } \\
\text { mas e características cultu- } \\
\text { rais similares. }\end{array}$ & 171 \\
\hline $\begin{array}{c}\text { Conceito } \\
\text { Enade }\end{array}$ & Avaliação >2 & $\begin{array}{l}\text { Avaliação com conceito de, } \\
\text { pelo menos, metade do valor } \\
\text { máximo que pode ser obtido. }\end{array}$ & 107 \\
\hline $\begin{array}{l}\text { Ranking de } \\
\text { avaliação } \\
\text { Enade }\end{array}$ & $\begin{array}{l}\text { Universidades } \\
\text { ranqueadas até } \\
\text { a } 100^{\circ} \text { posição }\end{array}$ & $\begin{array}{l}\text { Avaliação anual das universi- } \\
\text { dades do país baseada em } \\
\text { dados nacionais e internacio- } \\
\text { nais e em duas pesquisas de } \\
\text { opinião do Datafolha em } \\
\text { cinco aspectos: pesquisa, } \\
\text { ensino, mercado, internacio- } \\
\text { nalização e inovação }\end{array}$ & 25 \\
\hline
\end{tabular}

Desta forma, as três primeiras etapas de filtragem visam uma caracterização coerente ao estudo e à sua aplicabilidade; e os dois últimos filtros, garantem a qualidade dos cursos autenticados por avaliações imparciais nacionais, estando para além das métricas necessárias a este trabalho.

Com base nas filtragens realizadas, foram encontrados 25 cursos, apresentados no Quadro 4, com a respectiva categoria administrativa, a localização da IES e campi, a data de início de funcionamento, bem como o conceito de avaliação no Enade, a carga horária mínima para cumprimento do curso e as vagas anuais ofertadas.

${ }^{1}$ Notas 1 e 2 são considerados desempenho insatisfatório; 3 razoável; e 4 e 5, bom. 
Quadro 4: Cursos de Arquitetura e Urbanismo elencados com base na filtragem. Fonte: Elaborado pela autora.

\begin{tabular}{|c|c|c|c|c|c|c|}
\hline IES & $\begin{array}{l}\text { Categ. Ad- } \\
\text { ministrativa }\end{array}$ & Cidade, UF & $\begin{array}{l}\text { Ano de funda- } \\
\text { ção do Curso }\end{array}$ & $\begin{array}{l}\text { Conceito } \\
\text { Enade }\end{array}$ & $\begin{array}{l}\text { Carga } \\
\text { hor. }\end{array}$ & $\begin{array}{l}\text { Vagas } \\
\text { anuais }\end{array}$ \\
\hline $\begin{array}{l}\text { Pontifícia Universidade Católica do } \\
\text { Rio Grande do Sul - PUCRS }\end{array}$ & Privada & $\begin{array}{l}\text { Porto Ale- } \\
\text { gre, RS }\end{array}$ & 01/08/96 & 4 & 3.825 & 120 \\
\hline $\begin{array}{c}\text { Universidade Católica de Pelotas - } \\
\text { UCPEL }\end{array}$ & Privada & Pelotas, RS & $01 / 08 / 91$ & 3 & 3.600 & 80 \\
\hline Universidade de Caxias do Sul - UCS & Privada & $\begin{array}{l}\text { Caxias do } \\
\text { Sul, RS }\end{array}$ & 04/03/96 & 4 & 3.960 & 150 \\
\hline $\begin{array}{c}\text { Universidade de Santa Cruz do Sul - } \\
\text { UNISC }\end{array}$ & Privada & $\begin{array}{l}\text { Santa Cruz } \\
\text { do Sul, RS }\end{array}$ & 01/03/99 & 4 & 3.810 & 55 \\
\hline $\begin{array}{c}\text { Universidade do Vale do Rio dos Si- } \\
\text { nos - UNISINOS }\end{array}$ & Privada & $\begin{array}{l}\text { São Leo- } \\
\text { poldo, RS }\end{array}$ & 06/03/72 & 3 & 3.830 & 360 \\
\hline $\begin{array}{c}\text { Universidade do Vale do Taquari - } \\
\text { UNIVATES }\end{array}$ & Privada & Lajeado, RS & 28/07/03 & 3 & 3.840 & 170 \\
\hline $\begin{array}{c}\text { Universidade Federal de Santa Maria } \\
\text { - UFSM }\end{array}$ & Pública & $\begin{array}{c}\text { Santa Maria, } \\
\text { RS }\end{array}$ & 01/03/93 & 5 & 4.290 & 30 \\
\hline $\begin{array}{c}\text { Universidade Federal do Rio Grande } \\
\text { do Sul - UFRGS }\end{array}$ & Pública & $\begin{array}{l}\text { Porto Ale- } \\
\text { gre, RS }\end{array}$ & 01/03/46 & 5 & 4.500 & 110 \\
\hline $\begin{array}{l}\text { Universidade Regional Integrada do } \\
\text { Alto Uruguai e Das Missões - URI }\end{array}$ & Privada & $\begin{array}{l}\text { Frederico } \\
\text { Westphalen, } \\
\text { RS }\end{array}$ & $27 / 02 / 12$ & 3 & 3.825 & 50 \\
\hline $\begin{array}{l}\text { Universidade Regional Integrada do } \\
\text { Alto Uruquai e das Missões - URI }\end{array}$ & Privada & $\begin{array}{l}\text { Santiago, } \\
\text { RS }\end{array}$ & $01 / 03 / 01$ & 3 & 3.825 & 35 \\
\hline $\begin{array}{l}\text { Universidade Regional Integrada do } \\
\text { Alto Uruguai e das Missões - URI }\end{array}$ & Privada & $\begin{array}{l}\text { Santo Ân- } \\
\text { gelo, RS }\end{array}$ & $22 / 02 / 11$ & 4 & 3.825 & 50 \\
\hline Centro Universitário SOCIESC & Privada & Joinville, SC & $10 / 02 / 05$ & 3 & 4.320 & 250 \\
\hline $\begin{array}{c}\text { Fundação Universidade o Estado de } \\
\text { Santa Catarina - UDESC }\end{array}$ & Pública & Laguna, SC & $01 / 02 / 08$ & 4 & 4.320 & 100 \\
\hline $\begin{array}{c}\text { Universidade do Sul de Santa Cata- } \\
\text { rina - UNISUL }\end{array}$ & Privada & $\begin{array}{l}\text { Florianópo- } \\
\text { lis, SC }\end{array}$ & 03/08/98 & 4 & 4.260 & 260 \\
\hline $\begin{array}{c}\text { Universidade do Sul de Santa Cata- } \\
\text { rina - UNISUL }\end{array}$ & Privada & Tubarão, SC & 03/08/98 & 3 & 4.260 & 200 \\
\hline $\begin{array}{l}\text { Universidade Federal de Santa Cata- } \\
\text { rina - UFSC }\end{array}$ & Pública & $\begin{array}{l}\text { Florianópo- } \\
\text { lis, SC }\end{array}$ & $01 / 03 / 77$ & 5 & 3.900 & 80 \\
\hline $\begin{array}{c}\text { Universidade Regional de Blumenau } \\
\text { - FURB }\end{array}$ & Pública & $\begin{array}{l}\text { Blumenau, } \\
\text { SC }\end{array}$ & $24 / 02 / 92$ & 3 & 4.878 & 110 \\
\hline $\begin{array}{c}\text { Centro Universitário Filadélfia - UNI- } \\
\text { FIL }\end{array}$ & Privada & $\begin{array}{l}\text { Londrina, } \\
\text { PR }\end{array}$ & $11 / 08 / 80$ & 3 & 4.320 & 100 \\
\hline $\begin{array}{c}\text { Pontifícia Universidade Católica do } \\
\text { Paraná - PUCPR }\end{array}$ & Privada & Curitiba, PR & 08/03/76 & 3 & 4.068 & 480 \\
\hline $\begin{array}{l}\text { Universidade Estadual de Londrina - } \\
\text { UEL }\end{array}$ & Pública & $\begin{array}{l}\text { Londrina, } \\
\text { PR }\end{array}$ & $14 / 08 / 79$ & 4 & 4.150 & 60 \\
\hline $\begin{array}{c}\text { Universidade Estadual de Maringá - } \\
\text { UEM }\end{array}$ & Pública & Maringá, PR & $20 / 03 / 00$ & 5 & 4.534 & 40 \\
\hline $\begin{array}{c}\text { Universidade Federal do Paraná - } \\
\text { UFPR }\end{array}$ & Pública & Curitiba, PR & $01 / 01 / 61$ & 5 & 4.590 & 60 \\
\hline Universidade Positivo - UP & Privada & Curitiba, PR & 07/02/00 & 4 & 4.200 & 210 \\
\hline $\begin{array}{c}\text { Universidade Tecnológica Federal do } \\
\text { Paraná - UTFPR }\end{array}$ & Pública & Curitiba, PR & 03/08/09 & 5 & 4.365 & 88 \\
\hline Universidade Tuiuti do Paraná - UTP & Privada & Curitiba, PR & $01 / 09 / 97$ & 4 & 4.000 & 150 \\
\hline
\end{tabular}


Na sequência foram analisados os objetivos de cada instituição, se há e em que momento são elaborados os projetos de espaços livres de lazer e recreação, parques ou praças, para entender sua distribuição dentro da grade curricular dos cursos e a relação com as atribuições e capacidades inerentes ao egresso de Arquitetura e Urbanismo.

\section{Resultados e discussões}

Voltando um pouco no tempo, nos anos 2000, Luiz Antônio Cunha, ao realizar observações sobre o panorama educacional brasileiro, comenta que a listagem de disciplinas e carga horária mínima estabelecida pelo conselho máximo de educação poderia dar lugar à indicação de conteúdos gerais — como unidades de estudo de modo a permitir flexibilidade, com base nas necessidades dos alunos, e não ocupar mais que a metade do tempo previsto para realização de cada curso de graduação (CUNHA, 2000).

Observando as grades curriculares, no ano de 2020, nota-se que esta perspectiva de mudança no ensino de graduação, ainda que pertinente, não se instaurou no Brasil. Nos cursos de Arquitetura e Urbanismo analisados, as grades curriculares das instituições de ensino superior são formadas principalmente pelas matérias determinadas pelo MEC - Ministério da Educação e Cultura - como componentes do currículo mínimo, assim sendo obrigatórias.

Analisando o objetivo desenvolvido por cada instituição de ensino superior para o egresso de Arquitetura e Urbanismo, no entendimento de que são as habilidades e competências constituintes do perfil profissional após finalização do curso, observase a existência de características cujo desejo de alcance é comum a todos:

- capacidade de elaboração de projetos;

- capacidade de resolução de problemas;

- capacidade de consideração de aspectos ambientais e ecológicos;

- formação interdisciplinar;

- responsabilidade social;

- uso de tecnologia, técnica, ética e criatividade no exercício da função.
Com base na Lei 5.194/1966, que regula o exercício da profissão do Arquiteto e Urbanista, compete a este profissional a realização de atividades referentes a edificações, conjuntos arquitetônicos e monumentos, arquitetura paisagística e de interiores, urbanismo, planejamento físico, urbano e regional (BRASIL, 1966).

Tendo em vista que é um conjunto de atividades complexas, para que o Arquiteto e Urbanista exerça as funções que the competem, sua formação profissional deve contemplar o desenvolvimento das habilidades em campos diversificados. Desse modo, as diretrizes curriculares têm o objetivo de garantir ao estudante o domínio das matérias necessárias para o desenvolvimento de suas atribuições.

Com relação às atividades que propiciem o conhecimento sobre o projeto de espaços livres de lazer e recreação urbanos, reafirma-se que a sua presença é geralmente vista nas disciplinas de paisagismo. Embora apenas 9, dos 25 cursos de graduação, especifiquem em sua matriz curricular online a disciplina responsável.

A presença de disciplinas de paisagismo, que é em média de 1,7 por instituição, geralmente é distribuída entre o $4^{\circ}$ e o $8^{\circ}$ semestre. Como $44 \%$ das instituições adota a realização de 2 disciplinas na grade curricular, elas são organizadas de modo que o aluno avance o grau de complexidade/área/escala e tenha o domínio das atividades projetuais inerentes ao processo.

Nota-se assim, que o projeto de espaços livres de lazer e recreação é normalmente ministrado na segunda matéria de paisagismo. Mas cabe lembrar que, o ato de projetar envolve a capacidade de associação de ideias, análise, conexões, avaliação e síntese; assim o aluno aumenta seu repertório por meio da projetação, da realização de pesquisas e conexões entre as diversas problemáticas às quais foi exposto durante o processo de projeto, seja ele arquitetônico, urbanístico ou paisagístico.

Do mesmo modo em paisagismo, e como metodologia geral adotada nos cursos de Arquitetura e Urbanismo, o aluno realiza projetos com níveis de complexidade crescentes, que podem ser relacionadas à área, escala e ao programa, de modo que, ao final de sua trajetória acadêmica, esteja apto a exercer os diversos desafios da prática projetual.

Esclarece-se que questões relacionadas ao programa, à organização do espaço, à relação do lote com o entorno, à estrutura e influência na utilização do espaço criado, fazem parte da complexidade do ato de projetar, seja em arquitetura, 
urbanismo ou paisagismo, e o entendimento destas relações nas diversas áreas auxilia o estudante a realizar conexões entre as diversas possibilidades que envolvem o processo de projeto.

De modo geral, a capacidade do arquiteto e urbanista de entender as etapas do processo projetual relativo as diversas áreas e complexidades que pode encontrar após formado, advém do ensino de projeto, tanto em arquitetura e urbanismo, quanto em paisagismo, aliado às demais disciplinas. Assim, o alcance dos objetivos ao egresso, definido pelas instituições, é dado pelo somatório das atividades realizadas durante o curso.

\section{Considerações finais}

A ascendente oferta de novos cursos de Arquitetura e Urbanismo no Brasil contextualiza a necessidade de reavaliação do processo de ensino de paisagismo. Com 799 cursos em funcionamento no país, tem-se cerca de 122.076 alunos formandose a cada ano. Este número, bastante expressivo, eleva as preocupações sobre a qualidade do ensino e da formação, e corrobora para a justificativa de haver análises sobre os métodos de ensino e de projeto nos diversos campos, alinhando-os com a realidade social.

Nos cursos brasileiros de Arquitetura e Urbanismo há a forte presença de disciplinas de projeto, as quais são alinhadas às matérias profissionais fixadas pelo Ministério da Educação. Além disso, nota-se que os objetivos destinados ao perfil profissional das instituições consolidam-se pelo conjunto de disciplinas, que mesmo em diversos campos, complementam-se e contribuem para aptidão do egresso.

Com relação às disciplinas de projeto, ainda é possível constatar que o ensino é fortemente voltado à concepção arquitetônica, em função das demandas na carreira profissional, que majoritariamente advêm deste campo. Entretanto, com relação às disciplinas de paisagismo, o que se vê é a recente institucionalização das disciplinas com relação as demais, e a necessidade de que, mesmo em pequeno número, dotem o aluno de conhecimento sobre os muitos aspectos relacionados ao projeto da paisagem.

Por fim, depreende-se que o processo de ensino nos cursos de Arquitetura e Urbanismo é uma "ação em constante evolução" (MACEDO, 2007), os conteúdos se consolidam por diversos procedimentos, como a realização de pesquisas e a própria elaboração de projetos, e são organizados de modo que o aluno avance o grau de complexidade do programa, da área ou mesmo da escala.

\section{Referências}

ALMEIDA, Paulo Roberto de. Sobre o ensino do projeto. 2001. Dissertação (Mestrado) - Universidade Federal do Rio Grande do Sul, Faculdade de Arquitetura, Programa de Pesquisa e Pós-Graduação em Arquitetura, Porto Alegre, RS, 2001. Disponível em: https://lume.ufrgs.br/handle/10183/2084. Acesso em: 29 nov. 2018.

BRASIL. LEI 5.194 de Dezembro de 1966. Governo Federal, 1966. Disponível em: http://www.planalto.gov.br/ccivil_03/leis/15194.htm. Acesso em: 21 jan. 2021.

COSTA, Lúcio. Considerações sobre arte contemporânea. 1952. Disponível em: http://www.jobim.org/lucio/handle/2010.3/4097. Acesso em: 17 jul. 2020.

CUNHA, Luiz Antônio. Ensino superior e universidade no Brasil. In: 500 anos de educação no Brasil. Belo Horizonte, MG: Autêntica, 2000. Disponível em: http://edisciplinas.usp.br/pluginfile.php/1176223/mod_resource/content/1/Cunha_Ensino_Superior_e_Universidade_no_Brasil.pdf. Acesso em: 20 jan. 2021.

FEGHALI, Maria Elisa Marangoni. O Ensino de Projeto: Desafios e possibilidades em arquitetura Paisagística. 2013. Tese (Doutorado) - Universidade Federal do Rio de Janeiro, Programa de Pós-Graduação em Urbanismo, Rio de Janeiro, RJ, 2013. Disponível em: https://sucupira.capes.gov.br/sucupira/public/consultas/coleta/trabaIhoConclusao/viewTrabalhoConclusao.jsf?popup=true\&id_trabalho=420110.

Acesso em: 18 dez. 2018.

MACEDO, Silvio Soares. O paisagismo moderno brasileiro - além de Burle Marx. Paisagens em debate, São Paulo, n. 01, 2003. Disponível em: http://www.fau.usp.br/depprojeto/gdpa/paisagens/artigos/2003SilvioM-Burle.pdf. Acesso em: 21 dez. 2018.

MACEDO, Silvio Soares. Ensino de projeto de paisagismo (e por que não?), de urbanismo e projeto de arquitetura. In: 0 lugar do projeto no ensino e na pesquisa em arquitetura e urbanismo. Rio de Janeiro, RJ: Contra Capa, 2007.

MAHFUZ, Edson da Cunha. Reflexões sobre a construção da forma pertinente. Arquitextos, São Paulo, n. 1, p. 1-19, 2004. Disponível em: https://www.vitruvius.com.br/revistas/read/arquitextos/04.045/606. Acesso em: 18 set. 2018. 
MAHFUZ, Edson da Cunha. A pesquisa e suas possíveis relações com o projeto.

In: $O$ lugar do projeto no ensino e na pesquisa em arquitetura e urbanismo.

Rio de Janeiro, RJ: Contra Capa, 2007.

MEC, Ministério Da Educação e do Desporto. Portaria № 1.770, de 21 de dezembro de 1994. Disponível em: http://www.lex.com.br/doc_351157_PORTARIA_N_1770_DE_21_DE_. Acesso em: 4 mar. 2019.

E-MEC, MINISTÉRIO DA EDUCAÇÃO. Cadastro Nacional de Cursos e Instituições de Educação Superior: e-MEC. 2020. Disponível em: http://emec.mec.gov.br/. Acesso em: 1 jan. 2019.

PIÑÓN, Helio. Representação Gráfica do edifício e construção visual da arquitetura. Arquitextos, São Paulo, SP, n. 104.02, 2009. Disponível em: http://www.vitruvius.com.br/revistas/read/arquitextos/09.104/81/pt. Acesso em: 31 jan. 2019.

ROBBA, Fabio; MACEDO, Silvio Soares. Praças brasileiras. São Paulo, SP: EDUSP, 2002.

ROSANELI, Alessandro Filla. Apontamentos sobre o ensino de paisagismo nos cursos de arquitetura e urbanismo da região sul do Brasil. Paisagem e Ambiente, São Paulo, SP, n. 35, p. 199-219, 2015. Disponível em: http://www.revistas.usp.br/paam/article/view/105480. Acesso em: 4 mar. 2019.

VARGAS, Heliana Comin. Ensino/aprendizagem em arquitetura e urbanismo: mitos e métodos. In: $O$ lugar do projeto no ensino e na pesquisa em arquitetura e urbanismo. Rio de Janeiro: Contra Capa, 2007.

VIDIGAL, Emerson José. Um estudo sobre o ensino de projeto de arquitetura em Curitiba. 2004. Dissertação (Mestrado) - Biblioteca Digital de Teses e Dissertações da Universidade de São Paulo, São Paulo, 2004. Disponível em: http://www.teses.usp.br/teses/disponiveis/16/16131/tde-03052005-165841/. Acesso em: 31 jan. 2019. 